\title{
A LITERATURA NO CONTEXTO DA REVOLUÇÃO ESTÉTICA CONCEBIDA POR JACQUES RANCIĖRE
}

\author{
Nadier Pereira dos Santos ${ }^{1}$ \\ Université Paris 8 Vincennes - Saint-Denis \\ (i) https://orcid.org/0000-0002-1129-5276 \\ Joana Kelly Marques de Souza² \\ Universidade Federal do Rio Grande do Norte (UFRN) \\ (D) https://orcid.org/0000-0002-5335-9653
}

\section{RESUMO:}

A partir da perspectiva dos três regimes de identificação das artes propostos por Jacques Rancière, a literatura ocupa um lugar central na superação do regime poético, ou representativo, pelo regime estético. Para Rancière, o realismo de escritores como Hugo, Balzac, Stendhal e Flaubert subverte as hierarquias e pressupostos normativos vigentes no regime poético das artes. A partir desses autores, qualquer assunto ou qualquer pessoa, isto é, pertencente a qualquer condição social, podem vir a ser tratados como objeto literário sério, o que pode ser encarado enquanto a democracia em literatura. Também se valendo de análises de Erich Auerbach, o presente trabalho tem por objetivo explicitar como esse processo se deu, tentando mostrar por meio de alguns exemplos a maneira pela qual a literatura passou a ser desenvolvida em um espaço no qual as hierarquias dos temas e das ocupações sociais são quebradas e no qual se passa a denunciar a igualdade sensível de qualquer um. De um ponto de vista político-filosófico, Rancière promove aproximações à universalidade do juízo estético kantiano e à posterior proposta de Schiller no que diz respeito a uma educação estética da humanidade que retira dessa igualdade sensível o princípio de uma nova liberdade.

PALAVRAS-CHAVE: Jacques Rancière; Erich Auerbach; Realismo romanesco; Friedrich Schiller.

\footnotetext{
${ }^{1}$ Doutorando na Université Paris 8 Vincennes - Saint-Denis, Paris - França. Bolsista da CAPES - Proc. n 99999.001461/2015-00. E-mail: nadiers@yahoo.com.br

${ }^{2}$ Mestranda do Programa de Pós-graduação em Ciências Sociais da Universidade Federal do Rio Grande do Norte. E-mail: joanakellymarques@yahoo.fr
} 


\title{
LITERATURE IN THE CONTEXT OF THE AESTHETIC REVOLUTION IMAGINED BY JACQUES RANCIËRE
}

\begin{abstract}
From the perspective of the three regimes of identification of the arts put forth by Jacques Rancière, literature has a central role in overcoming the poetic, or representative, regime, with the aesthetic regime. According to Rancière, the realism of writers like Hugo, Balzac, Stendhal and Flaubert subverts hierarchies and existing normative assumptions in the poetic regime of the arts. Starting with these authors, any subject or any person - that is, belonging to any social condition - could become a serious literary object, which can be viewed as democracy in literature. Also taking the analyses by Erich Auerbach into consideration, this article aims to describe how this process took place, trying to show through some examples the way in which literature started to be developed in a space where the hierarchies of themes and social occupations were broken and where the sensitive equality of everyone started to be related. From a politicphilosophical point of view, Rancière promotes approaches to the universality of Kantian aesthetic judgment and the subsequent proposal of Schiller with respect to an aesthetic education of humanity that draws the principle of a new freedom from this sensitive equality.
\end{abstract}

KEYWORDS: Jacques Rancière ; Erich Auerbach ; Roman realism; Friedrich Schiller.

\section{Introdução}

Jacques Rancière identifica na tradição ocidental três regimes de identificação das artes: o regime ético das imagens, o regime poético, ou representativo, das artes e o regime estético das artes. De modo a situar a discussão que se pretende desenvolver aqui, faz-se necessário introduzir ao longo do trabalho algumas breves noções a respeito dos dois últimos. Comecemos com algumas observações a respeito do regime poético.

O regime poético, ou representativo, das artes é caracterizado por toda uma normatividade a partir da qual certas práticas são reconhecidas enquanto pertencentes a uma arte e apreciadas, nos limites dessa arte, como boas ou ruins, adequadas ou não. Esse regime é denominado poético no sentido de identificar as artes no interior de uma classificação de maneiras de fazer e de apreciar imitações benfeitas. Ele é representativo pelo fato de que é a noção de representação ou de mimesis que organiza as maneiras de fazer, ver e julgar.

Nesse regime, o fato da arte é, portanto, posto no par poiesis/mimesis. Aqui se encontra a concepção aristotélica da mimesis na 
qual "é o feito do poema, a fabricação de uma intriga que orquestra ações representando homens agindo, que importa, em detrimento do ser da imagem, cópia interrogada sobre seu modelo" (RANCIÈRE, 2005, p. 30, ênfase no original). Rancière faz questão de insistir que o princípio mimético não aponta no sentido de se fazer cópias parecidas com seus modelos, pois ele antes isola, no domínio geral das maneiras de fazer, "[...] certas artes particulares que executam coisas específicas, a saber, imitações" (2005, p. 30). Isso significa que as artes miméticas não mais se enquadram, como em Platão, na verificação habitual de seus usos ou na legislação de uma verdade. Por isso, segundo o autor, "o princípio de ficção que rege o regime representativo da arte é uma maneira de estabilizar a exceção artística, de atribuí-la a uma tekhne, o que quer dizer duas coisas: a arte das imitações é uma técnica e não uma mentira" (2005, p. 65). Dessa forma, é delimitado um domínio consistente de imitações e normatizadas as condições de inclusão nele. Com efeito, no regime poético as artes são identificadas no interior de uma classificação que dirá respeito a elementos como:

[...] separação do representável e do irrepresentável, distinção de gêneros em função do que é representado, princípios de adaptação das formas de expressão aos gêneros, logo, aos temas representados, distribuição das semelhanças segundo princípios de verossimilhança, conveniência ou correspondência, critérios de distinção e de comparação entre as artes etc. (RANCIÈRE, 2005, p. 31)

Importante notar que, para Rancière, antes de submeter as artes à semelhança, a mimesis representará “[...] o vinco na distribuição das maneiras de fazer e das ocupações sociais que torna as artes visíveis" (2005, p. 31). De modo a tornar isso mais claro, lembre-se que o classicismo, em suas diversas manifestações, definia formas de expressão altas e baixas, separava o trágico e o cômico, o sublime e o baixo. A regra estética exigia a separação do que é quotidiano e baixo do elevado e sério. Da mesma forma, proibia, por exemplo, relatar certas relações entre pessoas de posição social elevada e pessoas de origem humilde. Ainda dentro dessa lógica, um nobre não seria atacado por baixas paixões como o medo, tampouco estaria bêbado ou sentiria sede ou fome. Por isso os heróis eram representados normalmente por figuras aristocráticas, uma figura de baixa posição social seria indigna do trágico, para ela estava reservado o cômico, assim como os traços grotescos. É justamente a partir daí que a lógica representativa "[...] entra numa relação de analogia global com uma hierarquia global das ocupações políticas e sociais [...]" (RANCIÈRE, 2005, p. 32). Retomando, isso explica porque a mimesis não é um procedimento artístico que submete as artes à semelhança, e sim um regime de visibilidade das artes que 
autonomiza as artes e articula essa autonomia a uma ordem geral das maneiras de fazer e das ocupações.

\section{Mimesis:}

Complementando, destaca-se o que escreve Erich Auerbach em

A partir do Classicismo francês e, sobretudo, após o absolutismo, não somente o tratamento do quotidiano-real tinha se tornado muito mais limitado e decoroso, mas também a atitude que se tinha diante dele privava-se, por assim dizer, fundamentalmente, do trágico e do problemático. [...] um objeto da realidade prática podia ser tratado de forma cômica, satírica, didático-moralizante; certos objetos de campos bem circunscritos e determinados do contemporâneo e quotidiano atingiam até o nível estilístico mediano do comovente; mas não se ia além. A vida real-quotidiana, mesmo das camadas médias da sociedade, era considerada como de estilo baixo [...] (AUERBACH, 2013, p. 430)

É nesse sentido que Rancière observa que "[...] o primado representativo da ação sobre os caracteres, [...] a hierarquia dos gêneros segundo a dignidade dos seus temas, e o próprio primado da arte da palavra, da palavra em ato, entram em analogia com toda uma visão hierárquica da comunidade" (2005, p. 32). Isso significa que no regime poético, ou representativo, das artes o estatuto privilegiado de que gozavam algumas poucas maneiras de fazer não se devia a certa excelência que lhe fosse intrínseca, mas antes a seu lugar no quadro de uma configuração social específica.

Nesse contexto, deve-se observar a influência, sobretudo, da Poética de Aristóteles, mas também das obras classicistas baseadas em uma estética normativa que observava rígidas noções como proporção, ordem e harmonia. Em suma, segundo Rancière, esse caráter normativo

[...] encontra suas legitimações teóricas primeiras na elaboração aristotélica da mimesis, seu emblema na tragédia clássica francesa, e sua sistematização nos grandes tratados franceses do século XVIII [...]. No cerne desse regime, havia certa ideia do poema como disposição ordenada de ações, tendendo para sua resolução através do confronto de personagens que perseguiam fins conflitantes e que manifestavam em sua fala suas vontades e sentimentos segundo todo um sistema de conveniências. Tal sistema mantinha o saber sob o domínio da história e o visível sob o domínio da palavra, numa relação de contenção mútua do visível e do dizível. (RANCIÈRE, 2009, p. 49)

O presente artigo se dispõe a verificar brevemente como na concepção de Rancière o realismo romanesco de escritores como Hugo, 
Balzac, Stendhal e Flaubert se insere no contexto de subversão dessas hierarquias e pressupostos normativos do regime poético das artes.

\section{A revolução estética}

De acordo com Auerbach, o Romantismo, que surgira muito antes na Alemanha e na Inglaterra, e cujas tendências estavam se preparando há muito tempo também na França, se desenvolve por completo após 1820. Victor Hugo e seus amigos reivindicaram o princípio da mistura de estilos como marca do seu movimento. Nele o contraste com o tratamento clássico dos temas e com a linguagem literária clássica se manifestava de modo mais evidente. No entanto, Auerbach percebe na formulação de Hugo, em sua mistura do sublime com o grotesco, algo exacerbadamente antitético. Para o crítico, o sublime e o grotesco são polos estilísticos que não consideram o real. Com efeito, Hugo não buscava representar a realidade dada de maneira compreensiva, "[...] antes ressalta, nos temas históricos ou contemporâneos, os polos estilísticos do sublime e do grotesco ou também outras contradições éticas ou estéticas, e o faz com tanto vigor que eles se entrechocam com violência [...]" (AUERBACH, 2013, p. 419). A consequência retirada disso pelo crítico é que embora surjam efeitos fortes, dada a poderosa força de expressão de Hugo, são inverossímeis e, como reprodução da vida humana, falsos. Por isso, algumas páginas depois Auerbach afirma que considera a mistura do sério com a realidade quotidiana muito mais decisiva, autêntica e importante na forma de Stendhal e Balzac que na do grupo de Hugo. Entretanto, o crítico não deixa de destacar que a irrupção da seriedade trágica e existencial no Realismo, tal como encontrada nesses dois autores, se relaciona de maneira estreita com o movimento romântico da mistura dos estilos. O que interessa destacar aqui é o fato de que uma nova escrita começa a ocupar o lugar outrora ocupado por gêneros poéticos tradicionais. A esse respeito, Rancière escreve:

[...] os escritores desse tempo sonham, como Victor Hugo, com um novo grande gênero que substituiria o encadeamento temporal pela simultaneidade espacial, fazendo estar em uma mesma cena as grandezas aristocráticas, as manobras dos homens da sombra, os divertimentos da boemia e o elã dos plebeus rumo a novos céus. O drama é para eles esse novo gênero, feito da mescla dos gêneros e representando a mescla das condições, como aquela das ações espetaculares e dos sentimentos íntimos, em suma, "a mescla no palco do que está misturado na vida [...] um motim ali e uma conversa de amor aqui” (Hugo). ${ }^{3}$ (RANCIÈRE, 2011, p. 72-73) ${ }^{4}$

\footnotetext{
${ }^{3}$ As citações em língua estrangeira apresentadas em notas foram livremente traduzidas pelos autores deste artigo.

4 “ $[. .$.$] les écrivains de ce temps rêvent, comme Victor Hugo, d'un grand genre nouveau qui$ substituerait la simultanéité spatiale à l'enchaînement temporel, en faisant tenir sur une
} 
Porém, como se sabe, foi o gênero romanesco, com sua forma abrangente e elástica, que mais se identificou com esse anseio formado por tantos elementos. Rancière observa que nesse período a natureza dos eventos que compõem a ficção sofre mudanças. Os critérios segundo os quais a excelência da ficção era julgada passam a ser contestados por práticas de escrita que promovem certos deslocamentos e transformações, nem sempre levados a cabo de forma deliberada, na ordenação interna que subordinava os detalhes à perfeição do conjunto, nos encadeamentos de causas e de efeitos que asseguravam a inteligibilidade da narrativa através de seu desenvolvimento temporal. A ficção passa então a apresentar novos personagens, outros encadeamentos temporais, outra forma de realidade ou de necessidade (RANCIÈRE, 2014a, p. 08-10). De acordo com o autor, esse processo se insere num contexto bastante amplo iniciado no final do século XVIII no qual ocorreram profundas mudanças das formas de experiência sensível, das maneiras de perceber e de ser afetado, assim como do modo de inteligibilidade dessas reconfigurações da experiência.

É justamente aqui que entramos no âmbito do regime estético das artes, no qual Rancière situa as práticas artísticas contemporâneas. Nesse regime, a identificação da arte não se dá mais por uma distinção no interior das maneiras de fazer, "[...] mas pela distinção de um modo de ser sensível próprio aos produtos da arte" (RANCIÈRE, 2005, p. 32). Com a passagem do regime poético para o estético, o que Rancière denomina revolução estética, a absoluta singularidade da arte é afirmada ao mesmo tempo em que todo critério pragmático dessa singularidade é destruído, isto é, a estética normativa do regime poético é posta em causa. A arte doravante está desobrigada de toda e qualquer regra específica, de toda hierarquia de temas, gêneros e artes.

Para Rancière, a palavra estética remete ao modo de ser específico daquilo que pertence à arte, ao modo de ser de seus objetos, e não a uma teoria da sensibilidade, do gosto ou do prazer dos amadores de arte. $\mathrm{Na}$ concepção do autor, estética nesse contexto não remete à disciplina que se ocupa da arte, mas a um modo de pensamento que se desenvolve acerca das coisas da arte e que procura dizer em que elas consistem enquanto coisas do pensamento. Essa conclusão é amparada pela investigação que o autor desenvolve acerca da recente genealogia da palavra estética, levada a cabo por meio de uma revisita a toda a tradição que abrange reflexões de nomes como Kant, Schlegel, Schelling, Schiller e Hegel.

même scène les grandeurs aristocratiques, les manœuvres des hommes de l'ombre, les amusements de la bohème et l'élan des plébéiens vers des cieux nouveaux. Le drame est pour eux ce genre nouveau, fait du mélange des genres et représentant le mélange des conditions, comme celui des actions spectaculaires et des sentiments intimes, en bref 'le mélange sur la scène de ce qui est mêlé dans la vie [...] une émeute là et une causerie d'amour ici' (Hugo)." 
Contudo, deve-se afirmar logo de saída que Rancière alerta que, embora essa tradição da estética filosófica tenha se empenhado em pensar esse regime de identificação específico da arte, ela não o criou. Esses autores não inventaram "[...] a ruptura da ordem hierárquica que definia quais temas e quais formas de expressão eram ou não dignos de entrar no domínio de uma arte"5 (RANCIËRE, 2004, p. 20). Eles não inventaram nenhuma das reconfigurações que definem o regime estético, porém, “[...] elaboraram o regime de inteligibilidade no seio do qual elas se tornaram pensáveis. Eles apreenderam e conceituaram a fratura do regime de identificação no qual os produtos da arte eram percebidos e pensados, a ruptura do modelo de adequação que as normas da mimesis asseguravam entre poiesis e aisthesis" "(RANCIÈRE, 2004, p. 20). Sob o nome de estética eles apreenderam e pensaram o deslocamento fundamental: de agora em diante as coisas da arte se identificam cada vez menos segundo critérios pragmáticos de maneiras de fazer e passam a se vincular de forma crescente a uma identificação em termos de maneiras de ser sensíveis.

Dado esse percurso de formulação de um modo de inteligibilidade das reconfigurações da experiência, no regime estético as coisas das artes passam a ser identificadas por pertencerem a um regime específico do sensível. No entanto, há mais que isso, pois a tradição estética filosófica revisitada por Rancière abre caminho para pensar um sensível que é habitado por uma potência heterogênea, constituindo assim a estética enquanto o pensamento do "[...] sensorium paradoxal que permite de agora em diante definir as coisas da arte" (2004, p. 22). Em A partilha do sensível, Rancière escreve que esse sensível, "[...] subtraído a suas conexões ordinárias, é habitado por uma potência heterogênea, a potência de um pensamento que se tornou ele próprio estranho a si mesmo: produto idêntico ao não-produto, saber transformado em não-saber, logos idêntico a um pathos, intenção do inintencional etc.” (2005, p. 32). Será justamente essa identidade dos contrários que definirá o próprio da arte do regime estético, um regime novo e paradoxal de identificação das coisas da arte.

De acordo com Rancière, essa ideia de um sensível estranho a si mesmo, sede de um pensamento que se torna estranho a si mesmo, é o núcleo invariável das identificações da arte que configuram originalmente o pensamento estético. Esse novo regime de identificação da arte marcado pela relação entre as produções conscientes da arte e as formas involuntárias da experiência sensível é observável, por exemplo, nas especulações de

\footnotetext{
5 “[...] la rupture de l'ordre hiérarchique qui définissait quels sujets et quelles formes d'expression étaient ou non dignes d'entrer dans le domaine d'un art."

6 “[...] ils ont élaboré le régime d'intelligibilité au sein duquel elles sont devenues pensables. Ils ont saisi et conceptualisé la fracture du régime d'identification dans lequel les produits de l'art étaient perçus et pensés, la rupture du modèle d'adéquation que les normes de la mimesis assuraient entre poiesis et aisthesis."

7 “[...] sensorium paradoxal qui permet désormais de définir les choses de l'art."
} 
Kant ou de Schelling. No primeiro, a "ideia estética" e a teoria do gênio são marcas da relação, sem relação, entre os conceitos da arte e a ausência de conceito da experiência estética; no segundo, a teorização da arte como unidade de um processo consciente e de um processo inconsciente. $\mathrm{O}$ gênio kantiano ilustra bem essa dualidade, porquanto "ele é o poder ativo da natureza que opõe sua própria potência a qualquer modelo, a qualquer norma, ou melhor, que se faz norma. Mas, ao mesmo tempo, ele é aquele que não sabe o que faz, que é incapaz de prestar contas" (RANCIËRE, 2009 , p. 27). O mesmo ocorrendo com as autodefinições das artes próprias à idade moderna, o que pode ser ilustrado pelo caso do inconsciente do artista expresso pela prática surrealista ou pelo cinema de Bresson e o uso de seus "modelos", também concebidos pelo duplo encontro entre o ativo e o passivo, o voluntário e o involuntário.

A partir de então, a arte não pode ser pensada sem sua dupla face contraditória, pois suprimir essa contradição do pensamento é suprimir igualmente a arte e o sentimento estético. Finalmente, pode-se dizer que essa tradição da estética filosófica pensou essa revolução sobre o modo de um desafio para o pensamento, por isso, "de Kant à Adorno, passando por Schiller, Hegel, Schopenhauer ou Nietzsche, o discurso estético não terá outro objeto que o pensamento dessa relação desafinada" ${ }^{8}$ (RANCIÈRE, 2004, p. 17). Em suma, é nesses termos que estética passa a designar formas específicas de experiência e inteligibilidade associadas às artes. A consequência é que o regime estético das artes revoga o princípio, característico do regime poético, que unia a beleza a critérios de execução, classificação e apreciação. A beleza se dá agora sem conceito, o que doravante, e isto é o mais importante a realçar aqui, vem a estabelecer uma problemática relação entre arte e não arte.

Para Rancière, o momento inaugural de recusa da mimesis foi com frequência denominado realismo, o qual não significando de modo algum a valorização da semelhança, mas antes "[...] a destruição dos limites dentro dos quais ela funcionava" $(2005$, p. 35$)$. Destacando a mudança de postura que caracterizou esse momento, o autor escreve:

Quando são publicados, Madame Bovary ou A educação sentimental são imediatamente percebidos como "a democracia em literatura", apesar da postura aristocrática e do conformismo político de Flaubert. Até mesmo sua recusa em confiar à literatura uma mensagem é considerada como um testemunho da igualdade democrática. Ele é democrata, dizem seus adversários, na sua opção por pintar em vez de instruir. Essa igualdade de indiferença é consequência de uma opção poética: a igualdade de todos os temas, é a negação de toda relação de necessidade entre uma forma e um conteúdo

8 “De Kant à Adorno, en passant par Schiller, Hegel, Schopenhauer ou Nietzsche, le discours esthétique n'aura pas d'autre objet que la pensée de ce rapport désaccordé."

A literatura no contexto da revolução estética concebida por Jacques Rancière - Nadier Pereira dos Santos; Joana Kelly Marques de Souza 
determinados. Mas esta indiferença, o que é ela afinal senão a igualdade de tudo que advém numa página escrita, disponível para qualquer olhar? Essa igualdade destrói todas as hierarquias da representação e institui a comunidade dos leitores como comunidade sem legitimidade, comunidade desenhada tão somente pela circulação aleatória da letra. (RANCIÈRE, 2005, p. 19)

É assim que o realismo romanesco estabelece a igualdade de todos os temas, isto é, permite que qualquer tema possa ser objeto da arte. Mais ainda, é também a igualdade de qualquer pessoa, quando se considera que no original francês, l'égalité de tous les sujets, entra em jogo o duplo sentido da palavra sujet, que de acordo com o contexto pode significar tanto "sujeito" quanto "tema" ou "objeto", aquilo de que se trata. A partir do realismo romanesco qualquer assunto ou qualquer pessoa, isto é, pertencente a qualquer condição social, podem vir a ser tratados como objeto literário sério, daí a possibilidade de encará-lo nos termos de uma democracia em literatura. De acordo com Auerbach, essa nova atitude que investia de seriedade a expressão de toda uma nova sorte de objetos teve um desenvolvimento progressivo, uma vez que exigiu uma espécie totalmente nova de estilo sério. Não se poderia transferir sem transição para os novos objetos os níveis antigos de percepção e de expressão, por isso, num momento inicial, as tentativas não poderiam deixar de vir acompanhadas de insegurança. Exemplo dessa dificuldade é dado por Cortázar ao comentar, "à margem dos exemplos franceses" (1998, p. 45), a reação "tão acadêmica" (1998, p. 45) da crítica literária russa, quando, em 1820, Alexandre Pushkin passa a escrever poemas e contos nos quais aparecem palavras como lama ou charuto.

Diante de tudo o que foi exposto até aqui, o que nos interessa a partir deste ponto é observar a partir de alguns exemplos como a democracia romanesca, a democracia indiferente das descrições da literatura realista, foi desfazendo as hierarquias e normatividades características do regime poético e tornando possível que uma série de elementos até então indignos de representação artística séria ganhasse influência crescente nos projetos de alguns escritores. Inicialmente, destaca-se um exemplo retirado de Mimesis, a descrição por Balzac de Madame Vauquer, dona da pensão de Le Père Goriot (1934), que aparece em cena "arrastando seus chinelos tortos" (BALZAC, citado em AUERBACH, 2013, p. 420):

O rosto velhusco, rechonchudo, do meio do qual surge um nariz de bico de papagaio; as pequenas mãos roliças, a figura redonda como um rato de igreja, o corpete demasiado cheio e flutuante, estão em harmonia com esta sala onde ressuma a desdita, onde se acaçapa a especulação, e cujo ar mornamente fétido a Mme Vauquer respira sem repugnância. [...] A gordura baça dessa pequena mulher é o produto desta vida, como o tifo é a consequência das exalações de um hospital. A sua anágua

A literatura no contexto da revolução estética concebida por Jacques Rancière - Nadier Pereira dos Santos; Joana Kelly Marques de Souza 


\begin{abstract}
de lã tricotada, que sobressai da sua saia, feita de um velho vestido, cujo recheio escapa pelos rasgos do tecido puído, resume o salão, a sala de jantar, jardinzinho, anuncia a cozinha e faz pressentir os pensionistas. Quando ela está lá, este espetáculo está completo. Com cerca de cinquenta anos, Mme Vauquer parece-se com todas as mulheres que tiveram desgraças. (BALZAC, citado em AUERBACH, 2013, p. 420, ênfase no original)
\end{abstract}

A democracia romanesca assinalada por Rancière se faz perceber nessa descrição que opta por privilegiar uma personagem e aspectos materiais que, longe de serem idealizados, tendem para o declínio, denotando pobreza e desgaste. Há mesmo algum apelo ao repugnante. As descrições de Balzac harmonizam a personagem com seu ambiente, um refletindo o outro, um complementando o outro. Mas há ainda mais, porquanto suas características se estendem mesmo ao ponto de revelar algo de seu passado ou de atingir seus pensionistas, dizer algo deles sem que sejam apresentados ao leitor, prenunciá-los. Toda a aparência de Madame Vauquer, toda a economia dos pormenores de sua descrição, é capaz de expressar um complemento ao narrador.

É nesse sentido que para Rancière o realismo romanesco é, sobretudo, a subversão das hierarquias da representação - o primado do narrativo sobre o descritivo ou a hierarquia dos temas - e a "[...] adoção de um modo de focalização fragmentada, ou próxima, que impõe a presença bruta em detrimento dos encadeamentos racionais da história" (2005, p. 35). A partir desse trecho de Le Père Goriot é possível perceber como é desfeita a lógica dos encadeamentos narrativos do regime poético em nome de uma escrita capaz de se apoderar de qualquer coisa do mundo, em uma nova atitude ante a realidade que a apresenta em sua pura presença ou que sobrecarrega os significados de seus elementos, fazendo deles os signos por meio do quais se traz à superfície uma época, uma sociedade ou uma história. No contexto da revolução estética, a ordenação ficcional deixa de priorizar o encadeamento causal para explorar a linguagem muda das coisas e a linguagem cifrada das imagens, favorecendo uma nova racionalidade da vida material que encontra suas primeiras manifestações ainda no Romantismo.

A clássica poética aristotélica consiste na ação e na representação de "homens que agem", a sequência de ações que coincide com uma mudança de sorte ou de saber dos personagens. A essa poética, a era romântica opõe uma poética dos signos a partir da qual o encadeamento causal segundo a necessidade e a verossimilhança deixa de ser valorizado em nome do "[...] poder de significação variável dos signos e dos conjuntos de signos que formam o tecido da obra" (RANCIÈRE, 2014b, p. 260). Rancière aponta que a partir da idade romântica a linguagem passa a penetrar na materialidade dos traços por meio dos quais se tornam visíveis o mundo 
histórico e social. Essa ligação das formas da arte com as formas da vida partilhada permite que todas essas formas se associem e se expressem mutuamente em infinitas combinações a partir das quais podem expressar a vida coletiva que atravessa e une todos os fatos, objetos comuns, gestos elementares, palavras e imagens, banais ou extraordinárias. As formas do quadro ou as frases do romance, assim como as roupas, as gretas de um muro ou o desgaste de uma fachada, entram numa relação de entreexpressividade. Isso é normalmente remetido por Rancière a uma fórmula de Novalis: tudo fala, o que quer dizer duas coisas: que cada forma sensível é um tecido de signos mais ou menos obscuros, presença capaz de significar o potencial da experiência coletiva que a traz à presença, e que cada uma dessas formas significantes pode entrar em relação com as demais para formar novos agenciamentos significantes. Assim, a partir desse regime de sentido no qual cada coisa fala duas vezes, na sua pura presença e na vasta multiplicidade de suas conexões virtuais, as experiências se comunicam entre si e constituem um mundo comum (Cf. RANCIÈRE, 2014b, p. 290-291). Segundo o autor, esse mundo comum, que é lido por críticos de arte como os Goncourt e por filósofos como Hegel ${ }^{9}$ nas telas de Rembrandt, Rubens ou Chardin e transposta para o universo romanesco por Hugo ou Balzac, encontrou seu historiador exemplar no romântico Jules Michelet. Em conformidade com isso, Roland Barthes destaca que Michelet "[...] descreve o multicolorido dos trajes, a alteração dos brasões e a mistura dos estilos arquitetônicos, no começo do século $\mathrm{XV}$, como significantes de um significado único: a divisão moral da Idade Média que está terminando [...]" (2012, p. 173).

Segundo Rancière, o mundo histórico e social se torna então visível pela materialidade dos traços, "[...] ainda que sob a forma da linguagem muda das coisas e da linguagem cifrada das imagens" (2005, p. 54). Consequentemente, muito diferente das grandes linhas narrativas, tudo passa a ser considerado. Configura-se uma nova maneira de contar histórias, aquela que dá “[...] sentido ao universo 'empírico' das ações obscuras e dos objetos banais" (2005, p. 55). A partir da revolução estética promovida pela literatura, o banal é valorizado e se vincula ao verdadeiro quando é arrancado de sua evidência para ser transformado em "[...] um hieróglifo, uma figura mitológica ou fantasmagórica.” (2005, p. 50). Assim, a nova maneira de contar histórias, a nova ficcionalidade, torna-se a circulação nessa paisagem de signos. A ordenação ficcional passa a ser uma ordenação de signos. Isso quer dizer que a poética romântica afirma simultaneamente a potência de enunciação inerente a todas as coisas mudas e o poder infinito de multiplicar seus níveis de significação. Segundo Rancière, e aqui

\footnotetext{
9 “"...] Hegel assinalando o verdadeiro tema da pintura de gênero holandesa: não as histórias de estalagem ou descrições de interiores, e sim a liberdade de um povo impressa em reflexos de luz [...]”. In: (RANCIÈRE, 2005, p. 36).
} 
podemos uma vez mais ter em mente o exemplo de Madame Vauquer, essa ordenação dos signos

\begin{abstract}
É a identificação dos modos da construção ficcional aos modos de uma leitura dos signos escritos na configuração de um lugar, um grupo, um muro, uma roupa, um rosto. É a assimilação das acelerações ou desacelerações da linguagem, de suas profusões de imagens ou alterações de tom, de todas suas diferenças de potencial entre o insignificante e o supersignificante, às modalidades da viagem pela paisagem dos traços significativos dispostos na topografia dos espaços, na fisiologia dos círculos sociais, na expressão silenciosa dos corpos. A "ficcionalidade" própria da era estética se desdobra assim entre dois polos: entre a potência de significação inerente às coisas mudas e a potencialização dos discursos e dos níveis de significação. (RANCIÈRE, 2005, p. 55)
\end{abstract}

Como foi possível ler anteriormente, a revolução estética cria as condições para a elaboração de uma ideia de pensamento que repousa sobre a afirmação fundamental de que há identidade entre o pensamento e o nãopensamento. Nesse processo, "a escrita literária se estabelece [...] como decifração e reescrita dos signos de história escritos nas coisas" (RANCIÈRE, 2009, p. 35) e um novo modelo de artista se estabelece, aquele que recolhe os vestígios e transcreve os hieróglifos pintados nas coisas obscuras e triviais, devolvendo-as sua potência poética e significante. Para esse artista,

\begin{abstract}
Não existem temas nobres e temas vulgares, muito menos episódios narrativos importantes e episódios descritivos acessórios. Não existe episódio, descrição ou frase que não carregue em si a potência da obra. Porque não há coisa alguma que não carregue em si a potência da linguagem. Tudo está em pé de igualdade, tudo é igualmente importante, igualmente significativo. (RANCIÈRE, 2009, p. 36-37)
\end{abstract}

Rancière defende que Balzac resume e exalta essa nova ideia de escrita no início de A pele de onagro, quando descreve a loja do antiquário "[...] como emblema de uma nova mitologia, de um fantástico feito exclusivamente da acumulação das ruínas do consumo" (2009, p. 36). Segundo o autor, Balzac também vai fazer ver que o poeta dos novos tempos é Cuvier, "[...] o geólogo, o naturalista, que reconstitui populações animais a partir de ossos, e florestas a partir de impressões fossilizadas" (2009, p. 36), e não Byron, o "repórter das desordens da alma" (2009, p. 36). Da mesma forma, Hugo, em Os miseráveis, conduz o leitor a um esgoto que diz tudo e reúne de modo indistinto tudo o que a civilização utiliza e rejeita, “[...] suas máscaras e insígnias, bem como seus utensílios cotidianos" (2009, p. 37). Esse poeta geólogo ou arqueólogo também afirma 
a condição paradoxal dessa hermenêutica: "[...] para que o banal entregue seu segredo, ele deve primeiro ser mitologizado" (2009, p. 37-38). A casa ou o esgoto falam, assim como o farão toda a economia freudiana do detalhe ou a mercadoria marxista, trazem consigo os rastros do verdadeiro, desde que primeiramente sejam "[...] transformados em elementos de uma mitologia ou de uma fantasmagoria"10 (2009, p. 38). O escritor geólogo ou arqueólogo recolhe os vestígios e transcreve os signos que dão testemunho de um mundo e escrevem uma história. Na sua prosa, a escrita muda das coisas revela a verdade de uma civilização ou de um tempo, faz pressentir o destino de um indivíduo ou de um povo.

Por fim, nesse contexto, Rancière escreve:

Quando Balzac instala o leitor diante dos hieróglifos entrelaçados na fachada instável e heteróclita de La maison $d u$ chat qui pelote ou o faz entrar, com o herói de A pele de onagro, na loja do antiquário onde se acumulam em desordem objetos profanos e sagrados, selvagens e civilizados, antigos e modernos, que resumem, cada um, um mundo; quando faz de Cuvier o verdadeiro poeta que reconstitui todo um mundo a partir de um fóssil, estabelece um regime de equivalência entre os signos do novo romance e os signos da descrição ou da interpretação dos fenômenos de uma civilização. Ele forja essa nova racionalidade do banal e do obscuro que se contrapõe às grandes ordenações aristotélicas e se tornará a nova racionalidade da história da vida material oposta às histórias dos grandes feitos e dos grandes personagens. (RANCIÈRE, 2005, p. 56)

Em Mimesis também se encontra o comentário sobre o desvio que configura a trajetória do herói de $O$ vermelho e o negro (1830). Julien Sorel, jovem ambicioso e apaixonado, filho de um pequeno-burguês, devido às suas habilidades, aptidões intelectuais e a uma série de intrincadas circunstâncias, que não deixaram de ser acusadas de inverossimilhança pelos críticos da época, deixa um seminário eclesiástico no interior da França para tornar-se secretário de um membro da alta aristocracia, o Marquês de La Mole, em Paris. Desde a juventude, Julien é entusiasmado pelas ideias de Rousseau e pelos acontecimentos da época napoleônica, desprezando as classes que dominam a França desde a queda de Napoleão. De acordo com Auerbach, em $O$ vermelho e o negro os personagens e suas relações estão estreitamente ligados às circunstâncias históricas da época, suas condições políticas e sociais estão desenvolvidas na ação de modo tão

\footnotetext{
${ }^{10}$ De acordo com Rancière, essa dimensão fantasmagórica do verdadeiro, pertencente ao regime estético das artes, desempenhou um papel essencial na constituição do paradigma crítico das ciências humanas e sociais, sendo a teoria marxista do fetichismo seu exemplo mais destacado, pois busca extrair a mercadoria de sua aparência trivial, transformando-a em objeto fantasmagórico a partir do qual se possa ler a expressão das contradições de uma sociedade.
} 
exato e real como nunca antes ocorrera em um romance. Além disso, para o crítico esse romance de Stendhal destaca-se por outro motivo, a saber: "o fato de encaixar de forma tão fundamental e consequente a existência tragicamente concebida de um ser humano de tão baixa extração social [...] na mais concreta história da época, e de desenvolvê-la a partir dela, constitui um fenômeno totalmente novo e extremamente importante" (2013, p. 408).

O fato é que, após inúmeros sucessos, a história de Julien, herói de natureza passional e altiva, terá um desfecho trágico. Em Aisthesis, Rancière dá ênfase à atitude de Julien no final do romance, quando, após todas as suas tentativas de adquirir uma condição social mais elevada, está preso e esperando a condenação à morte. Para o autor, somente nesse momento, após tudo perder, Julien pode por fim gozar a vida, de tal modo que nada mais quer saber a respeito de sua situação com a justiça ${ }^{11}$. Somente quando deixa de calcular seus gestos, palavras e atitudes, característicos de uma sociedade marcada pelos incontáveis cálculos dos fins e dos meios, Julien passa a estar fora da racionalidade causal, furtando-se à temporalidade que nela está implicada e podendo finalmente desfrutar a felicidade do momento.

Partindo daí, Rancière discutirá alguns desdobramentos políticofilosóficos. Quando já não há nada além da morte a esperar, Julien pode gozar a pureza de um tempo que não está permitido a um plebeu como ele. Diferentemente do aristocrata, o papel dos plebeus é fazer, fabricar objetos e prestar serviços materiais para suprir suas necessidades de sobrevivência, não fazer isso, antes que uma ausência de ocupação, é transgredir a hierarquia das ocupações. Rancière vê justamente essa transgressão no fato de Julien escolher passar seus últimos dias a passear por um estreito terraço e a fumar os excelentes charutos que lhe trazem. O fazer nada promove um campo específico de experiências sensíveis, além de separar os homens do trabalho dos homens do prazer $^{12}$. Assim, a atitude de Julien abole uma

\footnotetext{
11 "Deixem-me na minha vida ideal. Seus pequenos embustes, seus detalhes da vida real mais ou menos desagradáveis para mim, me tirariam do céu." Logo depois se encontra: "É estranho, contudo, que só tenha conhecido a arte de gozar a vida depois que vi seu termo tão perto de mim". (STENDHAL, 2003, p. 328)

12 Trazemos aqui um trecho do romance no qual se percebe claramente essa distinção: Aproximando-se de sua fábrica, o pai Sorel chamou Julien, com sua voz bem forte; ninguém respondeu. [...] se dirigiu ao barracão; aí entrando, procurou inutilmente Julien no lugar que ele deveria ocupar, ao lado da serra. Percebeu-o a um e meio ou dois metros mais acima, sentado a cavalo sobre uma das vigas. Em vez de vigiar atentamente a ação de todo o mecanismo, Julien lia. Nada era mais antipático ao velho Sorel; teria talvez perdoado a Julien sua frágil estatura, pouco adequada para os trabalhos de força e tão diversa da de seus irmãos; mas esta mania de leitura lhe era odiosa; ele não sabia ler.Foi em vão que chamou Julien duas ou três vezes. A atenção com que se entregava a seu livro, bem maior que o barulho da serraria, o impedia de escutar a terrível voz de seu pai. Enfim, apesar de sua idade, este saltou lestamente sobre a árvore submetida à ação da serra e daí para a viga transversal que sustinha o teto. Um golpe violento fez voar no regato o livro que Julien segurava; uma segunda pancada também violenta, dada em sua
} 
hierarquia das ocupações na igualdade descoberta da pura partilha de uma sensação ou emoção. Finalmente, a felicidade de Julien não se dá em conquistar a sociedade tal com esperava, mas em fazer nada, anulando "[...] as barreiras da hierarquia social e o tormento de afrontá-las, na igualdade da pura sensação, na partilha sem cálculo do momento sensível"13 (RANCIÈRE, 2011, p. 75-76).

Rancière vai associar esse estado suspensivo, esse estado sensível liberado dos interesses e das hierarquias do conhecimento e do prazer, ao que foi caracterizado por Kant como objeto da universalidade subjetiva do juízo estético. Kant viu nessa universalidade sem conceito o princípio de um sentido comum capaz de unir a todos. Além disso, Rancière acrescenta outra referência, pensada, aliás, a partir de Kant: a proposta de Schiller nos termos de uma educação estética da humanidade que retirava dessa igualdade sensível o princípio de uma nova liberdade, o que se oporia à revolução violenta das instituições políticas. Schiller propõe uma educação de cada um e de todos, suscetível de perturbar a distribuição tradicional dos corpos em comunidade, de anular a hierarquia sensível de duas humanidades: uma constituída por aqueles que se dedicam às ordens imediatas do dia, e outra composta por aqueles que, livres dessa coação vital, podem conceber "fins mais amplos", dedicar-se a atividades que encerram seu próprio fim, ou, simplesmente, nada fazer (Cf. RANCIÈRE, 2011, p. 69 e 2014a, p. 80-81).

Para Schiller, é mediante a educação estética, quando se encontra no "estado de jogo", contemplando o belo, que o homem pode desenvolver-se plenamente em suas capacidades intelectuais e sensíveis. O termo "jogo" se relacionaria à atividade que não tem outro fim além de si mesma, que não se propõe a apoderar-se de nada. Essa acepção tradicional do jogo foi sistematizada pela análise kantiana da experiência estética. Na Crítica da faculdade do juízo, o juízo de gosto é deduzido mediante o jogo subjetivo entre imaginação e entendimento que se caracteriza por uma dupla suspensão: a do poder cognitivo do entendimento determinando os dados sensíveis segundo suas categorias e a suspensão do poder da sensibilidade

cabeça, em forma de cacholeta, o fez perder o equilíbrio. Ia cair a quatro ou cinco metros abaixo, no meio das alavancas da máquina em ação, porém seu pai o reteve com a mão esquerda: - Muito bem, preguiçoso! Sempre lê seus malditos livros enquanto cuida da serra? Fique com eles à noite, quando vai perder seu tempo na casa do cura. Julien, embora aturdido pela força da pancada, e sangrando, aproximou-se de seu posto oficial, ao lado da serra. Tinha lágrimas nos olhos, menos por causa da dor física do que pela perda do livro que adorava. - Desça, animal, para que eu lhe fale. - O ruído da máquina impediu ainda Julien de ouvir a ordem. Seu pai, que descera, não querendo se dar ao trabalho de tornar a trepar no maquinismo, foi procurar uma vara comprida para derrubar nozes e lhe bateu no ombro. Mal Julien desceu, o velho Sorel, empurrando-o rudemente para a frente, levou-o para casa. "Deus sabe o que ele vai me fazer!", pensava o rapaz. Ao passar, olhou tristemente o regato onde caíra seu livro; de todos, era o que mais estimava, o Memorial de Santa Helena. (STENDHAL, 2003, p. 19)

13 “"...] les barrières de la hiérarchie sociale et le tourment de les affronter, dans l'égalité de la pure sensation, dans le partage sans calcul du moment sensible." 
impondo objetos de desejo. Esse estado de contemplação do belo, de jogo, no qual razão e sensibilidade atuam juntas sem se sobreporem, caracteriza, portanto, um estado de liberdade para o homem, pois através dele é possível libertar-se das determinações tanto dos sentidos quanto da razão. Daí a famosa passagem da décima-quinta carta d'A educação estética do homem na qual se lê que "[...] o homem joga somente quando é homem no pleno sentido da palavra, e somente é homem pleno quando joga", afirmação, aliás, que suportará "[...] o edifício inteiro da arte estética e da bem mais dificultosa arte de viver" (SCHILLER, 1989, p. 76, ênfase no original). Logo em seguida, Schiller acrescenta que essa afirmação há muito já vivia e atuava na arte e no sentimento dos gregos, que, guiados por sua verdade, transpunham para o Olimpo o que deveria ser realizado na terra, retirando

[...] da fronte dos deuses ditosos tanto a seriedade e o trabalho, que marcam o semblante dos mortais, quanto o prazer iníquo, que lhes alisa a face vazia; libertaram os perenemente satisfeitos das correntes de toda finalidade, dever ou preocupação, fazendo do ócio e da indiferença o invejável destino do estamento divino: um nome apenas mais humano para a existência mais livre e mais sublime. (SCHILLER, 1989, p. 76)

Rancière vai fazer menção à décima-quinta carta d'A educação estética do homem, mais especificamente ao momento no qual Schiller instala o leitor diante da estátua grega conhecida como a Juno Ludovisi. Para Schiller, diante dessa estátua, irresistivelmente seduzidos e mantidos à distância, "[...] encontramo-nos simultaneamente no estado de repouso e movimento máximos, surgindo aquela maravilhosa comoção para a qual o entendimento não tem conceito e a linguagem não tem nome" $(1989$, p. 77$)$. De acordo com Rancière, na concepção de Schiller, a Juno Ludovisi é uma forma sensível heterogênea em relação às formas ordinárias da experiência sensível, ela se dá em uma experiência específica que suspende as conexões ordinárias não somente entre aparência e realidade, mas também entre forma e matéria, atividade e passividade, entendimento e sensibilidade. O próprio da divindade é nada querer, é estar livre de qualquer combinação de meios e de fins a realizar, sua característica essencial é sua ociosidade. A especificidade artística da estátua da deusa provém de sua participação nessa ociosidade, nessa ausência de vontade. Diante dela, o espectador entra no estado de "livre jogo".

Para Rancière, no final da décima-quinta carta Schiller constrói um cenário de exposição que alegoriza um estatuto da arte e de sua política. Porém, o autor se questiona: como a atividade gratuita do jogo pode fundar ao mesmo tempo a autonomia de um domínio próprio da arte e a construção das formas de uma nova vida coletiva? Por que essa suspensão promovida pelo "livre jogo" funda ao mesmo tempo uma nova arte de viver, uma nova 
forma da vida em comum? Dito de outra forma, em que certa "politica" é consubstancial à definição da especificidade da arte? Em sua forma mais geral, a resposta seria: "[...] porque ela define as coisas da arte pelo pertencimento delas a um sensorium diferente daquele da dominação"14 (RANCIÈRE, 2004, p. 46). É a partir de uma experiência que suspende a oposição entre atividade do entendimento e passividade da sensibilidade que a educação estética de Schiller quer arruinar "[...] uma ideia da sociedade fundada sobre a oposição entre os que pensam e decidem e os que são destinados aos trabalhos materiais" (RANCIÈRE, 2005, p. 66). As categorias do jogo e do trabalho inscrevem no tecido da experiência sensível ordinária as formas da dominação ou da igualdade. De modo geral, "[...] a legitimidade da dominação sempre repousou sobre a evidência de uma divisão sensível entre humanidades diferentes"15 (RANCIÈRE, 2004, p. 47), o poder das elites se relacionava àquele da classe da inteligência sobre a classe da sensação, dos educados sobre o vulgo ignorante, dos sentidos das pessoas refinadas sobre os sentidos das pessoas comuns, dos homens da cultura, que possuem acesso a uma totalização da experiência vivida, sobre os homens da natureza, submetidos às fragmentações do trabalho e da experiência sensível. Em suma, as formas "[...] da experiência sensível estavam encarregadas de identificar a diferença das funções e dos lugares a uma diferença das naturezas"16 (RANCIÈRE, 2004, p. 47).

De acordo com Rancière, o que o "livre jogo" recusa é justamente essa divisão que identifica a ordem da dominação à diferença de duas humanidades. Ele manifesta uma liberdade e uma igualdade do sentir. É, portanto, a autonomia de uma forma de experiência sensível que surge como o germe de uma nova humanidade, de uma nova forma individual e coletiva de vida. Por isso, o desdém silencioso de Julien Sorel diante da morte transgride as hierarquias das ocupações, os recortes dos tempos e os horizontes de experiência sensível destinados a duas humanidades diversas ao suspender as concatenações de causas e efeitos ou de fins e meios "[...] em benefício da única felicidade de sentir, do único sentimento da existência [...]"17 (RANCIÈRE. 2011. p. 66). É assim que para Rancière o privilégio dos eleitos é posto à disposição de todos pela capacidade estética, pela descoberta da capacidade de qualquer um de viver qualquer tipo de experiência.

\footnotetext{
14 “[...] parce qu'elle définit les choses de l'art par leur appartenance à un sensorium différent de celui de la domination."

15 “[...] la légitimité de la domination a toujours reposé sur l'évidence d'une divition sensible entre des humanités différentes."

16 “[...] de l'expérience sensible étaient chargées d'identifier la différence des fonctions et des places à une différence des natures."

17 “[...] au profit du seul bonheur de sentir, du seul sentiment de l'existence [...]"
} 
Por fim, destacam-se aqui alguns procedimentos artísticos de Flaubert. Uma vez mais, a exposição parte do que se lê em Mimesis, quando Auerbach se dispõe a analisar o seguinte trecho de Madame Bovary:

\begin{abstract}
Mas era sobretudo às horas de refeição que ela não aguentava mais, nesta pequena sala do andar térreo, com a estufa que fumegava, a porta que rangia, os muros que ressumavam, as lajes úmidas; toda a amargura da existência parecia-lhe servida no seu prato e, como a fumaça do cozido, subiam do fundo de sua alma como que outras baforadas de enjoo. Carlos era vagaroso ao comer; ela mordiscava algumas avelãs, ou então, apoiada no cotovelo, divertia-se a fazer riscos com a ponta da faca no oleado. (FLAUBERT, citado em AUERBACH, 2013, p. 432)
\end{abstract}

Logo após destacar esse trecho, o crítico comenta:

A passagem constitui o ponto culminante de uma descrição cujo objeto é a insatisfação de Emma Bovary com a sua vida em Tostes. Longo tempo esperou um acontecimento repentino, que imprimisse uma nova direção a essa vida sem elegância, aventura, nem amor, no mais profundo da província, ao lado de um homem medíocre e enfadonho. [...] somente quando não vê mais esperança alguma de fugir desse mundo, surge-lhe nitidamente o que ele tem de desconsolado, monótono, cinzento, enfadonho, asfixiante e irremediável. (AUERBACH, 2013, p. 432)

Flaubert escolhe escrever de forma séria a respeito de uma provinciana cuja vida não possuiria nenhum interesse especial. Muito pelo contrário, tudo ao redor dela, os mínimos detalhes, reflete sua completa insatisfação. Flaubert subordina toda a cena à insatisfação de Emma, a partir dela, todo o resto ganha sentido. Variados elementos materiais e movimentos fortuitos como mordiscar uma avelã ou apoiar-se no cotovelo ganham total importância na cena. A narração, menos da ordem da sucessão temporal que da simultaneidade espacial, se detém neles, e, em grande medida, são eles os responsáveis por transmitir alguma mensagem ao leitor.

$\mathrm{Na}$ concepção de revolução estética de Rancière, às exigências aristotélicas do relato coordenado vem juntar-se e contrapor-se a exigência de uma crontralógica que interrompe a progressão da intriga para dar a sentir a potência do tempo vazio, um tempo dos fins suspensos. "A ação também tem os seus momentos de sonho", Rancière destaca essa frase de Hugo, mas não sem advertir que não se trata somente de interpor pausas na sucessão dos episódios, porquanto foi o próprio sentido de episódio que mudou. Uma nova intriga opõe-se à velha intriga narrativa, marcada pelo tempo dos meios e dos fins. Por seu modo de tratamento do tempo, seus relatos ganham consistência justamente a partir do tempo vazio, do tempo 
perdido da deambulação ou do tempo suspenso das epifanias. Foi essa potência pura do sensível que a literatura ganhou entre Flaubert e Virginia Woolf (Cf. RANCIÈRE, 2014b, p. 85-86).

Emma à janela, absorta na contemplação dos seus pés de feijão derrubados pela chuva. Em outra janela, Charles apoiado nos cotovelos, "[...] com o olhar perdido na preguiça de uma noite de Verão, nas rocas dos tintureiros e na água suja de um braço de rio industrial" (RANCIÈRE, 2014 b, p. 21). Para Rancière, em certo sentido, eram "planos de cinema" (2014b, p. 21) que enquadravam micronarrações flaubertianas desse tipo. Pela "fixidez sonhadora do quadro" (2014b, p. 22), esses enquadramentos flaubertianos eram resultado de um trabalho de escrita que contradizia as expectativas e as verossimilhanças narrativas.

A referência a Aristóteles se direciona à sua noção de fábula, isto é, “[...] o agenciamento de ações necessárias ou verossímeis que, pela construção ordenada do nó e do desenlace, faz passar as personagens da felicidade para a infelicidade ou da infelicidade para a felicidade" (RANCIÈRE, 2014b, p. 8), lógica que definia não só o poema trágico como a própria ideia de expressividade da arte. Direciona-se também à noção aristotélica de muthos: "[...] uma representação de homens que agem, um agenciamento de ações detentoras [...] de uma certa grandeza, de uma medida própria, um tempo que a subtrai ao tempo sem começo, sem meio, sem fim, do mundo" (2014b, p. 133, ênfase no original).

No trecho de Madame Bovary destacado acima, marido e mulher estão à mesa, a mais quotidiana das cenas se desenrola em um instante qualquer. Auerbach chama a atenção para o fato de que situações dessa natureza, "[...] anteriormente, só seriam concebíveis literariamente como parte de uma farsa, de um id́lio, de uma sátira" (2013, p. 437). Nada de extraordinário é narrado, assim como nada de extraordinário é narrado a propósito do passado imediato. Não há nem mesmo um conflito tangível, uma briga. $\mathrm{O}$ desespero de Emma não é advindo de uma causa determinada, carece de concreção, seus desejos são múltiplos, mas vagos. Embora ela veja e sinta tudo, é incapaz de dar forma e expressar para si mesma o que sente. Flaubert fornece ao leitor o quadro do mal-estar de Emma pondo-a no meio de um amontoado de sensações e emoções, de um sem-número de impressões confusas. Nas notáveis palavras de Auerbach: "Nada acontece, mas este nada tornou-se um algo pesado, surdo e ameaçador" (2013, p. 437). Ainda segundo Auerbach, um desespero como tal pode ter sempre existido, mas nunca antes se pensou em tratá-lo com seriedade em obras literárias. Essa tragicidade carente de forma, desencadeada pela própria situação, tornou-se apreensível literariamente somente através do Romantismo, mas "Flaubert deve ter sido o primeiro a representá-la junto a seres humanos de baixa formação espiritual e de baixo nível social" (2013, p. 437). 
No que diz respeito à postura de Flaubert diante do seu objeto, lê-se em Mimesis:

\begin{abstract}
Embora ouçamos o autor falar, ele não exprime qualquer opinião e não comenta. Seu papel limita-se a escolher os acontecimentos e a traduzi-los em linguagem, e isto ocorre com a convicção de que qualquer acontecimento, se for possível exprimi-lo limpa e integralmente, interpretaria inteiramente a si próprio e os seres humanos que dele participassem; muito melhor e mais inteiramente do que o poderia fazer qualquer opinião ou juízo que lhe fosse acrescentado. Sobre esta convicção, isto é, sobre a profunda confiança na verdade da linguagem empregada com responsabilidade, honestidade e esmero, repousa a arte de Flaubert. (AUERBACH, 2013, p. 435)
\end{abstract}

Segundo Auerbach, Flaubert, dotado de senso artístico crítico num grau pouco comum até na França e devotado a uma paciência fanática, pretende esquecer-se de si próprio e submergir nos objetos da realidade de modo que os objetos o preencham inteiramente. É desse modo que atinge a expressão linguística plena, capaz de apanhar os objetos em sua integridade e julgá-los imparcialmente, de fazê-los surgir tais como são. Desse ponto de vista, pode-se prescindir de qualquer análise por parte do escritor para fins de facilitar a compreensão e a ordenação mais exata do que é apresentado, assim como de uma teoria geral dos níveis, por meio da qual os objetos seriam graduados segundo a sua dignidade. O nível de estilo correspondente a cada objeto será atingido ao reproduzi-lo correta e exatamente. A própria representação do objeto traria à luz seus elementos, da mesma forma que a situação de Emma na cena em questão emana diretamente da cena apresentada.

Rancière também comenta as intenções estilísticas de Flaubert, mas o faz inicialmente por meio de um questionamento: ao afirmar seu poder único e absoluto, o que deve produzir esse estilo soberano do escritor? A resposta dada pelo filósofo é: "uma obra liberta de qualquer marca da intervenção do escritor, que possua a indiferença, a passividade absoluta das coisas sem vontade nem significação" (2014b, p. 193). Não se trata de imprimir a própria vontade nos objetos, mas de igualar-se ao seu contrário, de realizar-se no seu contrário ${ }^{18}$. No entanto, essa potência do insignificante só se realiza no intervalo aberto no seio da lógica representativa, aquela na qual se encontram histórias de indivíduos guiados pela economia dos fins e dos meios, perseguindo objetivos. O trabalho do estilo consistia, portanto, em revestir a exposição das ações desses indivíduos "[...] com a passividade do olhar vazio das coisas sem razão. E só alcançava esse objetivo ao tornar-

${ }^{18}$ Vinculando esse movimento ao regime estético das artes, Rancière alerta que não se trata de uma ideologia de artista que assim se exprime, mas antes de um regime de pensamento da arte marcado pela igualdade dos contrários. (Cf. RANCIÈRE, 2014b, p. 193-194) 
se ele próprio passivo, invisível, anulando tendencialmente a sua diferença com a prosa comum do mundo" (RANCIÈRE, 2014b, p. 20).

\section{Considerações finais}

Como resultado de todos esses deslocamentos, a barreira mimética é implodida, aquela que distinguia as maneiras de fazer arte das outras maneiras de fazer e separava suas regras da ordem das ocupações sociais. Como foi possível perceber em exemplos encontrados em obras de Balzac, Stendhal e Flaubert, a opção por tomar por objeto pessoas de qualquer origem social, em ambientes quaisquer, fazendo coisas quotidianas, ou por destacar elementos materiais do quotidiano se deu nesse contexto de denegação do que separava o alto do baixo, o representável do não representável em arte, assim como suas respectivas formas de apresentação. Assim, por exemplo, elementos como inventários extravagantes dos acessórios da vida dos pobres, interiores domésticos, vestimentas, descrições não idealizadas ou movimentos sutis do corpo passam a fazer parte da criação artística de forma significativa por meio de uma fragmentação que rivaliza com as grandes linhas do relato. Nesse contexto, o encadeamento das ações do poema trágico dá lugar à lógica da mescla das condições e da multiplicidade de ínfimos acontecimentos em meio aos quais se perde a ordenação da narração. Nesse percurso marcado por uma série de rupturas com o modelo normatizado e hierarquizado do regime poético e de formação do paradigma estético, "[...] o romance destrona o drama como arte exemplar da palavra, testemunhando a capacidade dos homens e das mulheres sem qualidade para sentir qualquer forma de aspiração ideal ou de frenesi sensual. Mas ele o faz ao preço de arruinar o modelo da história com suas causas e seus efeitos, e da ação com seus meios e seus fins [...]"19 (RANCIÈRE, 2011, p. 15).

É dentro dessa nova lógica, onde tudo pode suceder a qualquer um e onde qualquer situação ou tema podem ser indistintamente tomados pelo escritor, que Rancière vislumbra a possibilidade de que a partir dos traços, vestimentas ou gestos de um indivíduo qualquer uma época e uma sociedade possam ser lidas em Balzac, de que em Hugo o esgoto seja revelador de uma civilização ou de que em Flaubert a filha do fazendeiro e a mulher do banqueiro sejam capturadas pela mesma potencia do estilo como "maneira absoluta de ver as coisas" (Cf. 2005, p. 47). É dessa maneira que Rancière situa a literatura no processo de alteração do regime de percepção, afecção e pensamento que caracteriza a revolução estética. Para o autor, "[...] o pensamento é sempre em primeiro lugar um pensamento do pensável, um

19 “[...] le roman détrône le drame comme art exemplaire de la parole, en témoignant de la capacité des hommes et des femmes sans qualité à éprouver n'importe quelle forme d'aspiration idéale ou de frénésie sensuelle. Mais il le fait au prix de ruiner le modèle de l'histoire avec ses causes et ses effets, et de l'action avec ses moyens et ses fins [...]' 
pensamento que modifica o pensável acolhendo o que era impensável"20 (2011, p. 12). Foi justamente isso que ocorreu na literatura desse período, ela tornou visível e deu estatuto artístico a uma série de elementos que eram indignos do céu do que até então se conhecia como arte.

\section{Referências bibliográficas}

AUERBACH, Erich. Mimesis: a representação da realidade na literatura ocidental. São Paulo: Perspectiva, 2013.

BARTHES, Roland. O discurso da história. In: O rumor da língua. Tradução de Mario Laranjeira. São Paulo: WMF Martins Fontes, 2012. p. 163-180.

CORTÁZAR, Julio. Obra crítica/l. Tradução de Paulina Wacht e Ari Roitman. Rio de Janeiro: Civilização Brasileira, 1998.

RANCIÈRE, Jacques. Malaise dans l'esthétique. Paris: Galilée, 2004. - A partilha do sensível: estética e política. Tradução de Mônica Costa Netto. São Paulo: EXO experimental org.; Ed. 34, 2005. . $O$ inconsciente estético. Tradução de Mônica Costa Netto. São Paulo: Ed. 34, 2009. . Aisthesis: scènes du régime esthétique de l'art. Paris: Galilée, 2011. 2014a. Le fil perdu: essais sur la fiction moderne. Paris: La Fabrique, A fábula cinematográfica. Tradução Luís Lima. Lisboa: Orfeu Negro, 2014b.

SCHILLER, Friedrich. A educação estética do homem: numa série de cartas. Tradução Roberto Schwarz e Márcio Suzuki. São Paulo: Iluminuras, 1989.

STENDHAL. $O$ vermelho e o negro. Tradução Maria Cristina F. da Silva. São Paulo: Nova Cultural, 2003.

\section{Contribuição dos autores:}

Os autores Nadier Pereira dos Santos e Joana Kelly Marques de Souza participaram da discussão, revisão e redação do artigo. Todos os autores aprovaram a versão final do texto.

\footnotetext{
20 “[...] la pensée est toujours d'abord une pensée du pensable, une pensée qui modifie le
} pensable en accueillant ce qui était impensable." 